\title{
Los jóvenes estudiantes de escuela media y la generación del sentido histórico. Un estudio en un caso: una escuela de Várzea Grande y el narrar desde los cómics alusivos al encuentro entre indígenas y europeos durante la conquista de América
}

\author{
Doi:https://doi.org/ 10.25100/hye.v15i53.8739
}

Artículo recibido: 19-02-2018 Artículo aceptado: 07-05-2019

\section{Marcelo Fronza}

Es Licenciado en Historia de la Universidad Federal de Paraná (UFPR, Brasil), cuenta con una Maestría en Educación de la misma universidad y un Doctorado en Educación. En el momento cursa estudios postdoctorales en Enseñanza de Historia de la Universidad de Oporto - UPorto, Portugal.

Universidade Federal de Mato Grosso, Brasil.

Correo electrónico: fronzam34@yahoo.com.br

ORCID: 0000-0002-4512-7027

Forma de citar este artículo: Fronza, Marcelo. " Los jóvenes estudiantes de escuela media y la generación del sentido histórico. Un estudio en un caso: una escuela de Várzea Grande y el narrar desde los cómics alusivos al encuentro entre indígenas y europeos durante la conquista de América”. Historia y Espacio, vol. 15 n 53 (2019): 271-308. Doi.org/ 10.25100/hye.v15i53.8739.

Artículo Tipo 1: de investigación. 


\section{Losjóvenes estudiantes de escuela media y la generación del sentido histórico. Un} estudio en un caso: una escuela de Várzea Grande y el narrar desde los cómics alusivos al encuentro entre indígenas y europeos durante la conquista de América

Resumen: Por medio de una experiencia de investigación cualitativa basada en la Grounded Theory (Teoría fundamentada) investigo cómo los jóvenes estudiantes de escuela media pública (entre 16 y 18 años) de la ciudad de Várzea Grande, Mato Grosso, Brasil, generan sentido de orientación temporal a partir del enfrentamiento entre dos cómics con temas históricos. Eso con la preocupación de comprender cómo estos jóvenes estudiantes movilizan ideas metahistóricas sobre los procesos históricos ligados a la relación entre la interculturalidad y el nuevo humanismo ${ }^{1}$. Para eso he producido una herramienta de investigación cualitativa ${ }^{2}$ con la cual investigo las ideas históricas de jóvenes estudiantes de una escuela media por medio de la confrontación de dos cómics sobre los conflictos entre europeos e indígenas durante la conquista de América entre 1492 y 1550. La primera narrativa histórica gráfica, la versión A, llamada Conquista e colonização da América [Conquista y colonización de América], es un capítulo del libro de texto organizado como historia en cómics História Geral: História para a escola moderna [Historia general: Historia para la escuela moderna] ${ }^{3}$ escrito por el historiador brasileño Julierme de Abreu e Castro y diseñado por el dibujante argentino Rodolfo Zalla. La segunda narrativa histórica gráfica presentada en el instrumento de investigación, la versión B, llamada Colombo [Colón] $]^{4}$, es escrita y dibujada por el caricaturista italiano Francesco Tulio Altan. En conclusión, pude comprobar que estos jóvenes estudiantes movilizan algunas de las dimensiones fundamentales de estos artefactos de la cultura histórica que crean la posibilidad de la aprehensión del conocimiento histórico elaborado de forma intersubjetiva y humanista.

Palabras clave: Educación histórica, Interculturalidad, Cómics históricos, Conflictos entre indígenas y europeos.

1 Jörn Rüsen, Cultura faz sentido: orientações entre o ontem e o amanhã (Petrópolis: Vozes, 2014).

2 Michelle Lessard-Hébert, Gabriel Goyette y Gérald Boutin, Investigação qualitativa: fundamentos e práticas (Lisboa: Instituto Piaget, 2005).

3 Julierme de Abreu e Castro y Rodolfo Zalla, História Geral: História para a escola moderna (São Paulo: Ibep, 1971).

4 Francesco Tulio Altan, Colombo (Porto Alegre/São Paulo: LP\&M Editores, 1989). 


\section{Young high school students and the generation of historical sense. Case study: a Várzea Grande school and narration of the comics alluding to the encounter between indigenous and European people during the conquest of America}

Abstract: Through a qualitative research experience based in the Grounded Theory I investigate how young students of public high school (between 16 and 18 years old) of the city of Várzea Grande, Mato Grosso, Brazil, generate sense of temporal orientation from the confrontation between two comics with historical issues. This, with the concern to understand how these young students mobilize metahistorical ideas about the historical processes linked to the relationship between interculturality and the new humanism (see footnote 1). For this, I have produced a research tool based on methodological criteria of qualitative research (see footnote 2) where I investigate the historical ideas of young students of a high school through the confrontation of two comics about conflicts between Europeans and Indigenous during the conquest of America, which took place around 1492 and 1550. The first historical graphic narrative, A version, called Conquista e colonização da América [Conquest and the colonization of America] is a chapter of the textbook organized as historical comic book História Geral: História para a escola moderna [General History: History for modern school] (see footnote 3)written by the Brazilian historian Julierme de Abreu e Castro and drawn by the Argentine cartoonist Rodolfo Zalla. The second historical graphic narrative presented in the research instrument, the B version, called Colombo (see footnote 4), written and drawn by the Italian cartoonist Francesco Tulio Altan. In conclusion, I could see that these young students mobilize some of the dimensions of these artifacts of historical culture that create the possibility of the apprehension of historical knowledge elaborated in an intersubjective and humanistic way.

Keywords: History Education, Interculturality, Historical comic books, Clashes between Indigenous and Europeans. 


\section{Marcelo Fronza}

Los jóvenes estudiantes de escuela media y la generación del sentido histórico. Un estudio en un caso: una escuela de Várzea Grande y el narrar desde los cómics alusivos al encuentro entre indígenas y europeos durante la conquista de América

\section{Introducción}

Investigo las ideas históricas de jóvenes estudiantes de la educación media ${ }^{5}$ a través de los cómics desde la epistemología de la historia. Este trabajo es

${ }^{5}$ Comprendo la idea de jóvenes estudiantes como una categoría sociohistórica pautada en el concepto de cultura joven (o cultura juvenil) relacionada con su presencia en la cultura escolar. Según el historiador Eric Hobsbawm, la juventud sería el „locus tradicional“ de una cultura específica. Los jóvenes, comprendidos como sujetos conscientes de sí, son cada vez más reconocidos por la industria cultural. Sin embargo, esto no impide la „tensión“ entre las generaciones. La cultura juvenil urbana tiene un carácter claramente internacionalista, porque tanto las canciones como los cómics se han convertido en „marcas“ de la juventud contemporánea. Para François Dubet y Danilo Martuccelli, la juventud se constituye como una experiencia de masa ligada, tanto a la cultura juvenil como con la expansión masiva de la cultura escolar. En la medida en que se amplían los vínculos de los estudiantes con la forma escolar en el tiempo, también ocurre la ampliación de la experiencia de la juventud, que se está volviendo estructural en la sociedad occidental. La cultura juvenil está constituida por medio de los gustos, de los estilos y posibilita la expresión de sensibilidades sociales e ideológicas. Las canciones, los modos de vestir, los diversos lenguajes, políticas, morales y estéticas estructuran la experiencia juvenil y afrontan o ignoran los valores de la cultura escolar. La sociabilidad juvenil es selectiva en la cultura escolar al desarrollarse colectivamente en las franjas o fuera de las escuelas. Además, es duramente reprimida en los colegios populares y descuidada en las escuelas de las clases medias y altas de la población, ampliando así las contradicciones entre las formas de subjetivación de la juventud y las formas de internalización de la cultura escolar. En ese sentido, me opongo ontológica y epistemológicamente a la idea de adolescencia como una categoría psicopedagógica, pues esta no considera los componentes sociohistóricos que estructuran la cultura joven y la juventud en su praxis social y en la cultura escolar. Ver Eric J. Hobsbawm, Era dos extremos: o breve século XX (São Paulo: Companhia das Letras, 1995), 316 e 326. François Dubet y Danilo Martuccelli, En la escuela: sociología de la experiencia escolar (Buenos Aires: Editorial Losada, 1998), 330-333. 
producido a partir del grupo de profesores historiadores ligado al Laboratorio de Investigación en Educación Histórica de la Universidad Federal del Paraná (Lapeduh/UFPR) y también forma parte del proyecto de investigación Los jóvenes y las ideas de verdad histórica e intersubjetividad en la relación con las narrativas históricas visuales, vinculado al Grupo Investigador Educación Histórica: Consciencia histórica y narrativas visuales de la Universidad Federal de Mato Grosso (GPEDUH/ UFMT/CNPq).

Esta investigación se inserta en el conjunto de estudios relativos a la cognición histórica situada en la epistemología de la historia ${ }^{6}$, que tienen como principios y finalidades la propia ciencia de la historia y sirven de base para el área de trabajo de la educación histórica, un campo de investigación que estudia las ideas históricas de los sujetos en contextos de escolarización. Eso, de tal forma que está estructurada por investigaciones empíricas que dialogan con la teoría de la conciencia histórica ${ }^{7}$.

Con ello, a partir de una experiencia de investigación cualitativa basada en la Grounded Theory (Teoría fundamentada), estructurada como un estudio en un caso ${ }^{8}$, investigo cómo los jóvenes estudiantes de escuela media pública (entre 16 y 18 años) de la ciudad de Várzea Grande, Mato Grosso, Brasil, generan sentido de orientación temporal a partir del enfrentamiento entre dos cómics con temas históricos. Con este fin, he producido una herramienta de

6 Maria Auxiliadora Schmidt, “Cognição histórica situada: que aprendizagem é esta?”, en Aprender História: perspectivas da Educação Histórica, coordinado por Maria Auxiliadora Schmidt y Isabel Barca. (Ijuí: Unijuí, 2009), 28.

7 Las investigaciones relativas a la educación histórica están vinculadas al abordaje de una didáctica de la historia que tiene como objeto el aprendizaje histórico. De este modo, sólo es posible construir estrategias didácticas con generación de sentido de orientación temporal si el profesor parte de las ideas y narrativas históricas de los estudiantes. En ese sentido, esa concepción de aprendizaje se aparta de la idea de transposición didáctica, pues no desincretiza ni despersonaliza, por medio de metodologías de enseñanza, el conocimiento histórico de los estudiantes. Ver Jörn Rüsen, A razão histórica: Teoria da história: os fundamentos da ciência histórica (Brasília: UnB, 2001). Jörn Rüsen, Aprendizagem histórica: Fundamentos e paradigmas (Curitiba: W. A. Editores, 2012).

8 Entiendo que esta investigación realiza un estudio en un caso. Esto porque, siguiendo las investigaciones empíricas que dialogan con la teoría de la conciencia histórica, busco comprender cómo jóvenes estudiantes movilizan, a través de los cómics, la generación de sentido de orientación temporal desde un caso histórico (en el caso, la experiencia de violencia ocurrida durante la conquista de América) en el contexto de una cultura escolar específica. Un estudio de caso requeriría enfoques etnográficos de la escuela y sus clases que no me propuse realizar con profundidad en esta investigación. 
investigación cualitativa ${ }^{9}$ con la cual investigo las ideas históricas de jóvenes estudiantes de tres clases de segundo año en una escuela media ${ }^{10}$ desde la confrontación de dos cómics sobre los conflictos entre europeos e indígenas durante la conquista de América ${ }^{11}$, entre 1492 y 1550 . Busco comprender cómo estos jóvenes se orientan temporalmente desde la dimensión del sufrimiento humano del otro narrado por esos artefactos de la cultura histórica.

\section{Los cómics como artefactos de la cultura histórica de los jóvenes estudiantes}

Los cómics son narrativas históricas visuales que permiten la investigación de cómo los jóvenes perciben, interpretan y se orientan y se motivan históricamente en el flujo temporal entre el pasado, el presente y las expectativas de futuro. $\mathrm{Al}$ promover la comprensión histórica de los estudiantes, estas narrativas posibilitan que los jóvenes construyan históricamente sus posicionamientos políticos, estéticos, cognitivos y éticos ante los desafíos que se enfrentan en su praxis vital ${ }^{12}$.

A partir de la teoría de la conciencia histórica ${ }^{13}$, podemos afirmar que los cómics movilizan dos tipos de ideas históricas en los jóvenes estudiantes: los nombres propios y las imágenes semióforas. Los nombres propios son conceptos sustantivos que se refieren a los sujetos y situaciones históricas que se dirigen

9 Lessard-Hébert, Goyette y Boutin, Investigação qualitativa.

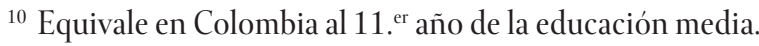

${ }^{11}$ Entiendo como conquista de América el proceso de invasión realizado por pueblos europeos de las tierras indígenas en el continente americano durante la primera parte del siglo XVI. Este proceso histórico fue realizado por medio de guerras, a veces genocidas, y encuentros (y hasta la miscegenación), siendo marcado por antagonismos y diálogos que demarcan desigualmente la forma violenta como la interculturalidad se constituyó en América. Sin embargo, como la prioridad de esta investigación es comprender las ideas metahistóricas y los posicionamientos de los jóvenes estudiantes en relación a ese proceso histórico violento mi concepción -y las de otros historiadores que movilizan otros conceptos como „descubrimientos“ o „expansión marítima europea“- sobre el mismo no tiene aquí valor heurístico.

${ }^{12}$ Jörn Rüsen, História viva: Teoria da História III: formas e funções do conhecimento histórico (Brasília: UnB, 2007).

${ }^{13}$ Esta teoría expone el principio de que la conciencia histórica es el conjunto de las operaciones mentales con las que los seres humanos interpretan su experiencia de la transformación temporal de su mundo y de sí mismos, de tal forma que puedan orientar intencionalmente su praxis vital en el tiempo. Ver Jörn Rüsen, A razão histórica: Teoria da história: os fundamentos da ciência histórica (Brasília: UnB, 2001), 57. 
a la estructuración de ideas e historias que proporcionan un hilo narrativo para la construcción de interpretaciones históricas ${ }^{14}$. Ya como portadoras de sentido o semióforas, las imágenes fascinan la conciencia histórica. Ellas tienen una función importante en la producción de interpretaciones históricas de la experiencia del tiempo y un papel relevante en la construcción de modelos interpretativos: pueden ser principios que intercomunican significados y generan sentido en la interpretación temporal. Las imágenes, símbolos y los nombres propios interfieren en la actividad rememorativa de la conciencia histórica, pero no son historias. Sin embargo, generan las mismas. Este fenómeno es más fuerte en el mundo contemporáneo, pues estamos marcados por una cultura de la imagen en el proceso de orientarnos en el tiempo.

La función narrativa de las imágenes y de los nombres propios se objetiva cuando se vuelven marcos para la formación de una interpretación histórica. Con eso, las imágenes ocupan el lugar de una historia. En otras palabras, son una abreviatura narrativa que proporciona sentidos y significados para algún tipo de narración histórica o elementos para la construcción de una historia a partir de evidencias ${ }^{15}$. Es la evidencia que proporciona la plausibilidad y la instancia de veto de esta validez, construyendo así una comprensión intersubjetiva entre los sujetos que narran.

La intersubjetividad internaliza en los estudiantes el proceso de constitución de la conciencia histórica colectiva de la humanidad en sus propias biografías en relación con las de los otros en el tiempo y en el espacio. Los principios que rigen la intersubjetividad son el diálogo y la capacidad de argumentar racionalmente, en los cuales los sujetos narran desde sus perspectivas históricas reconociendo como válidas las perspectivas históricas de los otros, reconstruyendo una multiperspectividad humanista. Con ello, la validez de la identidad histórica del sujeto es intrínseca a su igualdad en relación a la alteridad del otro ${ }^{16}$. Es

${ }^{14}$ Jörn Rüsen, Reconstrução do passado: teoria da História II: os princípios da pesquisa histórica (Brasília: UnB, 2007a), 93. Adriane de Quadros Sobanski et al, Ensinar e aprender História: histórias em quadrinhos e canções (Curitiba: Editora Base, 2010),24.

15 Jörn Rüsen, “¿Qué es la cultura histórica?: reflexiones sobre una nueva manera de abordar la historia”, Cultura histórica.es, (1994): 9-10, [Versión castellana inédita del texto original alemán en K. Füssmann, H.T. Grütter y J. Rüsen, eds.. Historische Faszination. Geschichtskultur heute. Keulen, Weimar y Wenen: Böhlau, 3-26], consultado en 01 nov. 2010, http://www. culturahistorica.es/ruesen/cultura_historica.pdf.

${ }^{16}$ Jörn Rüsen, Aprendizagem histórica: Fundamentos e paradigmas (Curitiba: W. A. Editores, 2012), 88-89, 107-108. 
de la intersubjetividad como principio que la categoría de la interculturalidad gana sentido.

La interculturalidad parte del principio del reconocimiento igualitario y humanista de la diferencia cultural que supera la comprensión etnocéntrica pautada en la tolerancia cedida, por lo civilizado, al no civilizado. Las luchas por el reconocimiento están en la base de los conflictos culturales contemporáneos. Sin embargo, es en el campo de esos conflictos que las posibilidades de comunicación intercultural se hacen valer, pues las culturas aprenden unas de otras y se modifican en la relación mutua, se interpenetran, se delimitan unas con otras, se combaten ${ }^{17}$ en el sentido de la palabra.

En este sentido, dos premisas problemáticas, predominantes en las academias occidentales, deben ser enfrentadas a partir del principio de la interculturalidad: la lógica de la "formación de sentido eurocéntrico" y de la "monadología cultural"18. En la primera lógica, el etnocentrismo se basa en un discurso que comprende la diferencia cultural como un principio asimétrico que se afirma a sí mismo en detrimento del otro. Es la base para las concepciones imperialistas y/o autoritarias de las relaciones culturales. La segunda lógica comprende que las civilizaciones se organizan en códigos semánticos propios y se relacionan superficialmente unas con otras. Esta idea se sustenta en el relativismo cultural de los pueblos. De cierta forma, es una reacción reversa a las concepciones etnocéntricas que no las supera.

Estos discursos académicos pueden ser superados cuando se tiene como principio el reconocimiento mutuo, en el cual el tiempo teleológico centrado en la línea cuatripartita eurocéntrica o en el caleidoscopio relativista del multiculturalismo es suplantado por la reconstrucción temporal policéntrica de la historia de la humanidad. Esta reconstrucción es posible en el momento en que los sujetos hacen uso de un entendimiento intercultural por medio de universales antropológicos y de valores humanistas e igualitarios presentes en todas las culturas humanas.

\footnotetext{
17 Jörn Rüsen, Cultura faz sentido: orientações entre o ontem e o amanhã (Petrópolis: Vozes, 2014), 296.

${ }^{18}$ Rüsen, Cultura faz sentido, 295-297.
} 


\section{Metodología: investigación sobre ideas interculturales de jóvenes estu- diantes sobre la conquista de América}

A partir de ese principio teórico, definí como público objetivo de esta investigación un grupo de 39 estudiantes $^{19}$, con edades de 16 a 18 años, de tres clases del segundo año de una escuela secundaria de la red pública de Mato Grosso, en Várzea Grande, ciudad perteneciente a la región metropolitana de Cuiabá, Mato Grosso, Brasil. Para ello, he producido una herramienta de investigación basada en los criterios metodológicos de la investigación cualitativa ${ }^{20}$ estructurada en la Grounded Theory (Teoría fundamentada) ${ }^{21}$. Los jóvenes de esa institución escolar pública fueron investigados en las mañanas de los días 12,19 y 21 de junio de 2017. Las referidas clases estaban compuestas por aproximadamente 30 estudiantes en cada una ${ }^{22}$. Esta herramienta de

${ }^{19}$ Estos jóvenes, veintidós mujeres y diecisiete hombres, viven en un barrio popular de la ciudad de Várzea Grande, en los suburbios de la ciudad de Cuiabá, Mato Grosso, Brasil, y la mayoría pertenecen a familias de la clase trabajadora de bajos ingresos del sector formal (público o privado) e informal de servicios. Treinta y ocho jóvenes siempre estudiaron en escuelas públicas, treinta y uno de ellos viven con sus padres. Los nombres de los estudiantes son ficticios y basados en personajes históricos caricaturizados en historias biográficas de resistencia y supervivencia al sistema capitalista en México y Ruanda.

${ }^{20}$ Lessard-Hébert, Goyette y Boutin, Investigação qualitativa.

${ }^{21}$ Grounded Theory es un método de investigación cualitativa que utiliza un conjunto de procedimientos sistemáticos para desarrollar inductivamente una teoría acerca de un fenómeno. Los resultados y conclusiones constituyen una formulación teórica de la realidad en estudio con el fin de proporcionar elementos útiles para la práctica en el área de estudio respectiva. La Grounded Theory defiende, por lo tanto, la necesidad de crear teoría derivada inductivamente del estudio del fenómeno, pero esta teoría es construida y desarrollada de forma provisional, y es confirmada a través de la recogida sistemática de datos y su análisis constante. Recogida de datos, análisis y teoría tienen una relación recíproca. Ver A. Strauss y J. Corbin, Basics of Qualitative Research. Grounded Theory, Procedures and Techniques (Newbury Park: Sage,1991).

${ }^{22}$ El número menor de estudiantes investigados (39) en relación al número total aproximado de las clases (aprox. 90) se debió a los altos niveles de desistimiento de los alumnos y a las faltas de algunos en los días en que el instrumento de investigación fue aplicado. La referida escuela, en el turno de la mañana, tiene solamente esas tres clases de segundo año de la escuela secundaria. La proporción del número de estudiantes investigados en relación al probable universo total de alumnos de las clases matutinas registradas sería de aproximadamente 1/3. La aplicación del instrumento de investigación fue realizada por las profesoras de las referidas clases a quienes agradezco mucho. 
investigación contiene dieciocho cuestiones directas y abiertas ${ }^{23}$ relativas a la confrontación de fragmentos de cinco páginas de dos cómics que tienen la pretensión de abordar didácticamente, basados en la historiografía, la temática de los conflictos entre los europeos y los indígenas ocurridos durante la conquista de América (1492 hasta 1550).

La primera narrativa histórica gráfica, la versión A (ver figura 1), denominada Conquista e colonização da América (Conquista y colonización de América), es un capítulo del libro de texto organizado como historia en cómics História Geral: história para a escola moderna" (Historia General: historia para la escuela moderna) escrito por el historiador brasileño Julierme de Abreu e Castro y diseñado por el caricaturista argentino Rodolfo Zalla ${ }^{24}$.

${ }^{23}$ El cuestionario con dieciocho ítems presentes en la herramienta de investigación está dividido en cuatro secciones: 1) situación sociohistórica del estudiante de escuela media; 2) concepción de historia y de aprendizaje histórico de los jóvenes estudiantes a partir de los cómics; 3) producción de cómics por medio de las dos versiones presentadas; y 4) concepciones de verdad e interculturalidad de los jóvenes estudiantes a partir de las dos versiones de los cómics. Las preguntas que aparecen en este artículo forman parte de esta última sección. No presento aquí los otros ítems, pues son muchos y fueron y serán aboradadas en otros trabajos. Es importante destacar que la profesora de estas clases enseñó la temática de la conquista de América meses antes de la aplicación de ese instrumento, incluso haciendo uso del libro de texto de historia. Sin embargo, cuando se les preguntó a los estudiantes si se acordaban de este (o conocían este) contenido histórico, casi la totalidad de esos sujetos escolares negó haber tenido conocimiento del proceso histórico de la conquista de América antes de la aplicación del instrumento investigativo.

${ }^{24}$ Julierme de Abreu Castro y Rodolfo Zalla, História Geral - História para a Escola Moderna (São Paulo: Ibep, 1971). 
Figura 1. Versión A

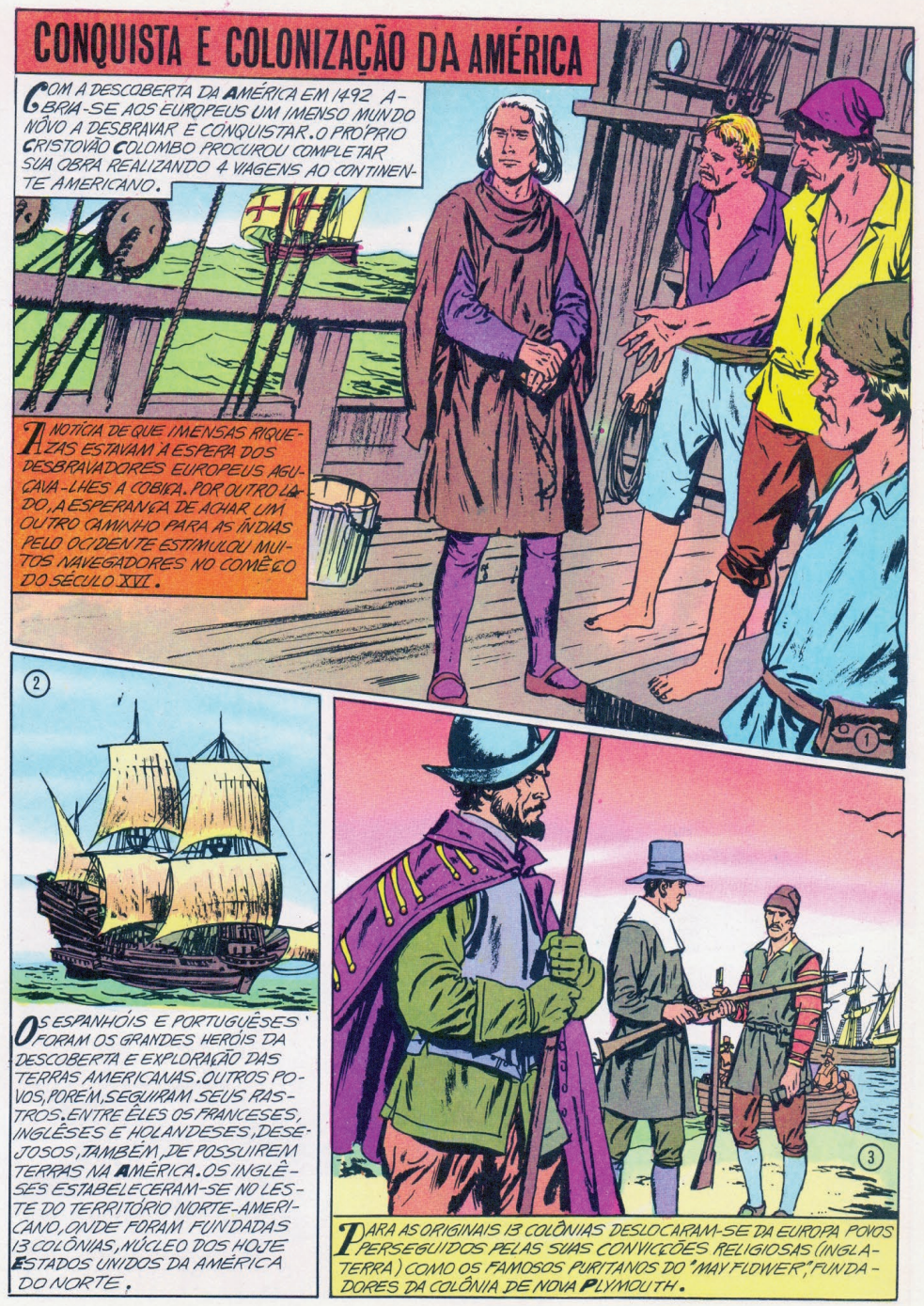

Fuente: Castro y Zalla, História Geral, 237.

Los libros de texto de Julierme de Castro, organizados como cómics, presentan una concepción de enseñanza de historia en la cual el abordaje se relaciona con la práctica de la memorización y de la retención de informaciones puntuales, a partir de una narrativa cuadripartita genérica que se presenta 
como una historia total, pero una historia eurocéntrica. Esta concepción de una enseñanza objetiva está relacionada con una comprensión de la historia como un conocimiento objetivo tradicional.

El estilo didáctico de los libros de texto de historia de Julierme de Castro, a partir de los cómics de Zalla, dispone los textos de forma que la atención del lector se desvía en relación a la narrativa histórica tematizada, ya que la inmovilidad de las imágenes sumadas al exceso de información escrita hace valorizar las concepciones eurocéntricas en relación a los conflictos entre indígenas y europeos durante la conquista de América. Esto porque dichas visiones eurocéntricas reconocen solamente las acciones de los conquistadores. Es evidente, sin embargo, verificar cómo los elementos estéticos de una narrativa histórica gráfica pueden, por medio de la imagen, potenciar las posibilidades de desarrollo del aprendizaje histórico, pero al mismo tiempo, la limitación de las características estéticas relativas al texto puede contraponerse y atenuar el poder imaginativo de las imágenes. Incluso con esas limitaciones históricas y didácticas, el libro de texto de Julierme de Castro y los cómics de Zalla marcaron una generación entera de estudiantes brasileños.

La orientación temporal es una categoría vital de la epistemología de la historia que debe ser trabajada en los libros de texto de historia y en los cómics. Sin embargo, aunque un libro de texto de historia organizado como cómic se presente sin un análisis en profundidad de su naturaleza estética, no quiere decir que los jóvenes que los lean no desarrollen un aprendizaje histórico elaborado.

La segunda narrativa histórica gráfica presente en el instrumento de investigación, la versión B (ver figura 2), llamada Colombo (Colón), guiada y dibujada por el caricaturista italiano Francesco Tulio Altan ${ }^{25}$, es un cómic que busca la reconstrucción del conocimiento histórico por medio de una contranarrativa pautada en una conciencia histórica crítico-genética e iconoclasta sobre los conflictos entre los indígenas y los europeos en el tiempo de la conquista de América.

${ }^{25}$ Altan, Colombo. 
Figura 2. Versión B

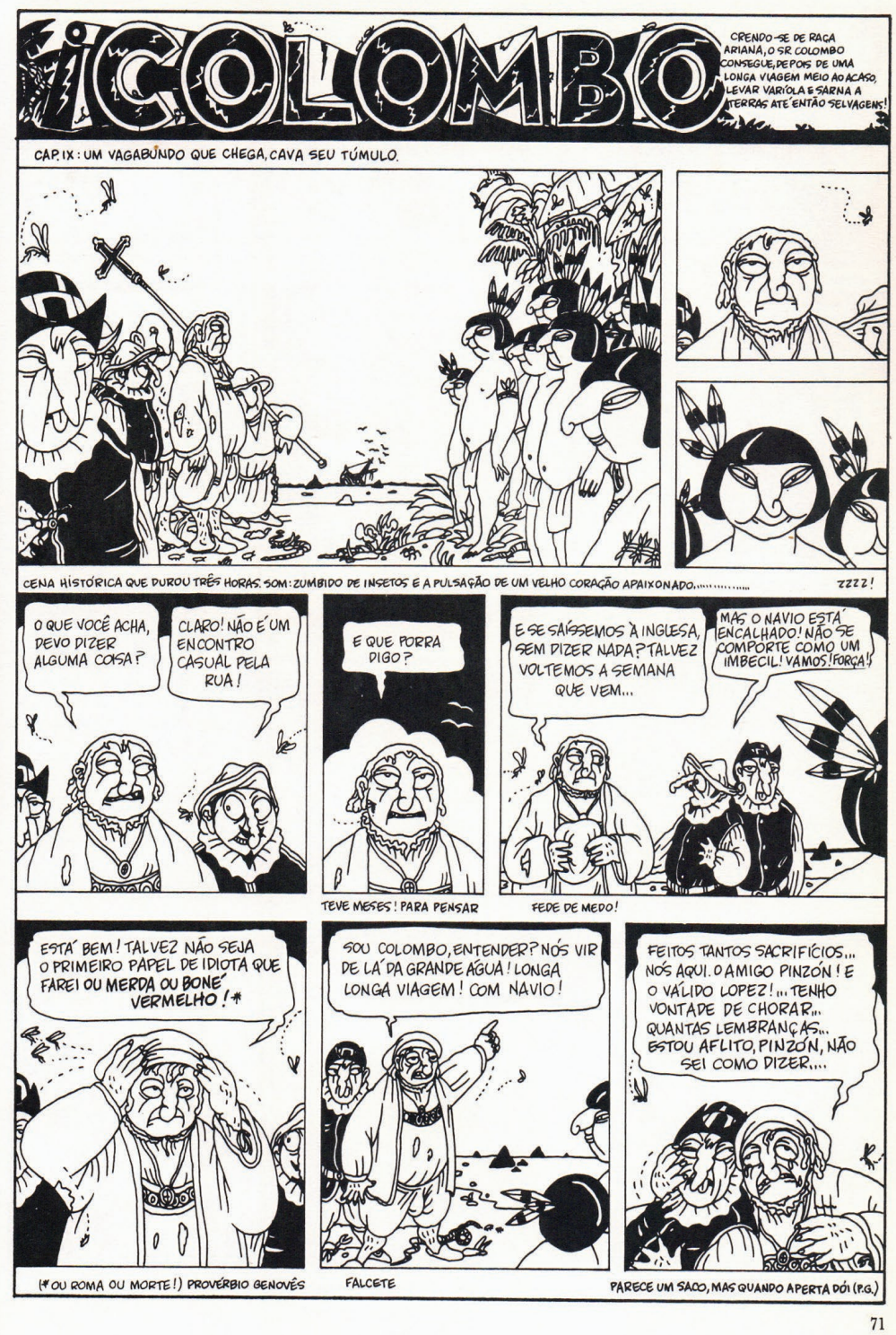

Fuente: Altan, Colombo, 71.

Este cómic narra el proceso de violencia sufrida y de resistencia practicada por los indígenas en los primeros contactos culturales originados por los 
primeros viajes del explorador europeo Cristóbal Colón al nuevo continente. La dimensión del sufrimiento humano narrada en este cómic posibilita a los jóvenes estudiantes la expansión de la intersubjetividad que es el principal parámetro para el aprendizaje histórico significativo. Ella se refiere a la ampliación de la capacidad de comunicar y articular memorias históricas a través de la formación de la identidad de los sujetos.

Siguiendo los criterios de Peter Lee ${ }^{26}$, estos cómics buscan controlar anacronismos en relación a los sujetos y las situaciones del pasado representadas.

\section{Resultados}

La primera pregunta investigativa fue inspirada en las del libro de texto inglés Skill in History ${ }^{27}$ y tiene como objetivo diagnosticar los contenidos sustantivos y los nombres propios ${ }^{28}$ que los jóvenes entienden como verdaderos. La cuestión a tratar es: "A partir de las versiones A y B, ¿cuáles son las situaciones del pasado que crees que realmente sucedieron? ${ }^{29}$ ¿Por qué?”.

${ }^{26}$ Peter Lee y Rosalyn Ashby, "Progression in Historical Understanding among Students Ages 7-14", en Knowing, Teaching and Learning History: National and International Perspectives, editado por Peter N. Stearns, Peter Seixas y Sam Wineburg, (New York: New York University Press, 2000), 199-222. Peter Lee, “Understanding History”, en Theorizing Historical Consciousness, editado por Peter Seixas (Toronto/Buffalo/London: University of Toronto Press, 2006), 129-164.

${ }^{27}$ Paul Shuter y John Child, Skills in History: Book 1: Changes. (Londres: Heinemann Educational Books, 1990).

28 Jörn Rüsen, Reconstrução do passado: Teoria da História II: os princípios da pesquisa histórica, (Brasília: UnB, 2007a), p. 93.

${ }^{29}$ Las expresiones „situaciones del pasado que realmente sucedieron“ o „experiencias que realmente sucedieron“ que aparecen recurrentemente en la composición y en el análisis de esta cuestión tienen como finalidad verificar, a partir del criterio de la plausibilidad empírica pautada en la teoría de la conciencia histórica, como los jóvenes estudiantes de enseñanza media demarcan como verdaderos determinados procesos históricos. A partir de esta y otras cuestiones (abordadas en otros trabajos) busco comprender las múltiples interpretaciones históricas de esos jóvenes estudiantes. No me preocupo aquí con las concepciones académicas relativistas o posmodernas (las cuales, en mi punto de vista, son ontológicas y epistemológicamente equivocadas) sobre la realidad o no de los procesos históricos ya que las investigaciones empíricas basadas en la teoría de la conciencia histórica las consideram refutadas científicamente. Esto es porque tanto la multiperspectividad de las experiencias históricas como la controversia de las interpretaciones y la pluralidad de las formas de orientación temporal se fundamentan en la realidad, veracidad y plausibilidad de los procesos 
La cuestión sobre cuáles situaciones del pasado consideran los jóvenes que realmente sucedieron llevó a la reducción de datos a partir de la tabla 1 , que expresa cómo esos sujetos movilizaron categorías cuando justificaron sus respuestas desde las tres operaciones de la conciencia histórica ${ }^{30}$ :

Tabla 1 - Las situaciones del pasado que realmente sucedieron

\begin{tabular}{|c|c|c|c|c|}
\hline $\begin{array}{c}\text { Operaciones } \\
\text { mentales }\end{array}$ & \multicolumn{2}{|c|}{ Categorías movilizadoras } & \multicolumn{2}{|c|}{$\begin{array}{c}\text { Número de } \\
\text { jóvenes * }\end{array}$} \\
\hline $\begin{array}{c}\text { Experiencia } \\
\text { histórica }\end{array}$ & $\begin{array}{c}\text { Explotación de } \\
\text { los indígenas por } \\
\text { los europeos }\end{array}$ & $\begin{array}{c}\text { Explotación del trabajo } \\
\text { Esclavización de los } \\
\text { indígenas por los europeos } \\
\text { Los europeos daban } \\
\text { herramientas para } \\
\text { los indios } \\
\text { Esclavitud de los negros } \\
\text { por los europeos }\end{array}$ & 12 & 18 \\
\hline & $\begin{array}{c}\text { Explotación de las mujeres } \\
\text { indígenas por los europeos }\end{array}$ & 3 & \\
\hline & $\begin{array}{c}\text { Matanza de los pueblos } \\
\text { indígenas por los europeos }\end{array}$ & 2 & \\
\hline
\end{tabular}

históricos. Ver Rüsen, A razão histórica y Bodo von Borries, "Multiperspectividade: pretensão utópica ou fundamento factível da aprendizagem histórica na europa?”, en Jovens e consciência histórica, coordinado por Maria Auxiliadora Schmidt, Marcelo Fronza y Lucas Pydd Nechi (Curitiba: W.A. Editores, 2016), 79-102.

${ }^{30}$ Rüsen, A razão histórica. Según Jörn Rüsen, la narración histórica es la expresión de la conciencia histórica movilizada por tres operaciones mentales. La operación de la experiencia histórica se objetiva en las relaciones entre el pasado y presente inferidos a partir de evidencias pautadas en fuentes y testimonios históricos. La operación mental de la interpretación histórica se refiere a los cuadros históricos de interpretación teórica que dan significado a las experiencias históricas. La operación de la orientación histórica proporciona el sentido orientación en el tiempo entre pasado, presente y futuro organizado por una idea histórica que estructura las interpretaciones y las experiencias históricas con miras a la construcción y continuidad por el sujeto de una identidad histórica pautada en el autoconocimiento y de una praxis social desde el otro. 
Los jóvenes estudiantes de escuela media y la generación del sentido histórico...

\begin{tabular}{|c|c|c|c|c|}
\hline \multirow[t]{2}{*}{$\begin{array}{l}\text { Operaciones } \\
\text { mentales }\end{array}$} & \multicolumn{2}{|c|}{ Categorías movilizadoras } & \multicolumn{2}{|c|}{$\begin{array}{l}\text { Número de } \\
\text { jóvenes * }\end{array}$} \\
\hline & & $\begin{array}{c}\text { Catequización de los } \\
\text { indígenas por los europeos }\end{array}$ & 1 & \\
\hline & $\begin{array}{l}\text { Conquistay } \\
\text { colonización } \\
\text { de América }\end{array}$ & $\begin{array}{c}\text { Encuentro entre } \\
\text { indígenas y europeos } \\
\text { Europeos (españoles, } \\
\text { portugueses, franceses, } \\
\text { ingleses y holandeses) } \\
\text { como héroes de } \\
\text { descubrimiento y } \\
\text { explotación de América } \\
\text { Españoles y portugueses } \\
\text { interesados en la } \\
\text { riqueza [de la India] } \\
\text { Napoleón Bonaparte, } \\
\text { Cristóbal Colón, } \\
\text { Hernán Cortés }\end{array}$ & 7 & 15 \\
\hline & & $\begin{array}{c}\text { Descubrimiento de Brasil } \\
\text { Llegada de los } \\
\text { portugueses a Brasil } \\
\text { Brasil fue abandonado } \\
\text { por los portugueses }\end{array}$ & 5 & \\
\hline & & $\begin{array}{l}\text { Llegada de los } \\
\text { españoles a América }\end{array}$ & 1 & \\
\hline & & Las 13 colonias & 1 & \\
\hline & & Llegada de los inmigrantes & 1 & \\
\hline & Conflictos y guerras & $\begin{array}{l}\text { Guerra de los indios } \\
\text { y los europeos }\end{array}$ & 6 & 9 \\
\hline
\end{tabular}




\begin{tabular}{|c|c|c|c|c|}
\hline $\begin{array}{l}\text { Operaciones } \\
\text { mentales }\end{array}$ & \multicolumn{2}{|c|}{ Categorías movilizadoras } & \multicolumn{2}{|c|}{$\begin{array}{l}\text { Número de } \\
\text { jóvenes* }\end{array}$} \\
\hline & & Peleas entre los europeos & 1 & \\
\hline & & $\begin{array}{l}\text { La lucha contra los aztecas } \\
\text { y los incas (México y Perú) }\end{array}$ & 1 & \\
\hline & & Robos & 1 & \\
\hline \multirow{5}{*}{$\begin{array}{l}\text { Interpretación } \\
\text { histórica }\end{array}$} & \multicolumn{2}{|c|}{ Relación con la verdad histórica } & \multicolumn{2}{|c|}{9} \\
\hline & \multicolumn{2}{|c|}{ Relación con la política } & \multicolumn{2}{|c|}{2} \\
\hline & \multicolumn{2}{|c|}{ Relación con el cambio histórico } & \multicolumn{2}{|c|}{1} \\
\hline & \multicolumn{2}{|c|}{ Relación con el trabajo } & \multicolumn{2}{|c|}{1} \\
\hline & \multicolumn{2}{|c|}{ Relación con la riqueza } & \multicolumn{2}{|c|}{1} \\
\hline \multirow{3}{*}{$\begin{array}{l}\text { Orientación } \\
\text { histórica }\end{array}$} & \multicolumn{2}{|c|}{ Relación estética con el pasado } & \multicolumn{2}{|c|}{7} \\
\hline & \multicolumn{2}{|c|}{ Relación con la interculturalidad } & \multicolumn{2}{|c|}{2} \\
\hline & \multicolumn{2}{|c|}{ Relación con el aprendizaje histórico } & \multicolumn{2}{|c|}{1} \\
\hline \multicolumn{3}{|c|}{ No respondieron } & \multicolumn{2}{|c|}{9} \\
\hline
\end{tabular}

Fuente: elaboración del autor, 2018.

\section{La experiencia histórica}

Para comprender las situaciones del pasado que los estudiantes interpretaron como experiencias históricas realmente ocurridas, construí a partir de esas respuestas tres categorías que coligan ${ }^{31}$ esos datos empíricos: la explotación de los indígenas por los europeos, la conquista y colonización de América y los conflictos y guerras.

\section{Explotación de los indígenas por los europeos}

Con respecto a este tema destaco que dieciocho veces los jóvenes investigados citaron formas de explotación de los indígenas, sea en relación al trabajo,

${ }^{31}$ W. H. Walsh, Introdução à filosofia da História (Rio de Janeiro: Zahar, 1978). 
al acoso sexual, a los genocidios o a imposiciones religiosas. La forma de explotación más citada, doce veces, es la relativa al trabajo.

[La versión] B. La parte que Pedro esclaviza a los indios. [La versión] A. La parte que los negros fueron esclavizados. (Madonna - 17 años - Várzea Grande).

La parte que ellos esclavizan a los indios. Los colocan a trabajar, hacer todo el servicio pesado. (Apollinaria - 17 años - Várzea Grande).

El trabajo y la catequesis de los indios. (Bosco - 17 años - Várzea Grande).

Para los jóvenes, la forma de explotación del trabajo al que los indígenas eran sometidos por los europeos es la esclavitud; incluso Madonna, basada en la versión A, informa que también los negros fueron esclavizados en Brasil. Es importante destacar que esta joven construye una inferencia anacrónica al sugerir que Pedro (Pedro Álvares Cabral) esclavizó a los indígenas en la época de su contacto en el 1500. Apollinaria entiende que la esclavización de los indígenas se refería a un trabajo pesado, mientras que Bosco vinculaba el trabajo a la imposición de la catequesis con relación a esos sujetos. Una inferencia que podemos constatar es que el concepto histórico ${ }^{32}$ o idea sustantiva $^{33}$ de esclavitud está muy presente en la conciencia histórica de los jóvenes investigados, lo que no dista de las concepciones historiográficas sobre el tema que tienden a llamar a los indios, explotados de cautivos o en régimen de cautiverio ${ }^{34}$. Otra forma de explotación humana fue citada tres veces por los jóvenes: la explotación sexual.

La situación de la matanza de los indígenas y la explotación de sus mujeres porque en todos los libros y películas de esa época siempre destacan ese acontecimiento. (Dolores - 17 años - Várzea Grande).

\footnotetext{
32 Jörn Rüsen, Reconstrução do passado: Teoria da História II: os princípios da pesquisa histórica (Brasília: UnB, 2007a), 94.

${ }^{33}$ Lee, "Understanding History", 130.

34 John M. Monteiro, Negros da terra: Índios e bandeirantes nas origens de São Paulo (São Paulo: Companhia das Letras, 1994), 36, 41, 52.
} 
Las situaciones donde los europeos daban herramientas para los indios y decían para ayudarlos. Y las situaciones donde los europeos se involucraban con los indios. (Marianne - 18 años - Várzea Grande).

La esclavitud de los indios, los portugueses conquistaron las mujeres de los indios. (Ricardo - 16 años - Várzea Grande).

Dolores y Marianne escribieron que la explotación sexual de las mujeres indígenas es una situación que debe ser destacada. Dolores identifica los asesinatos de indígenas y la explotación de las mujeres, el mismo hecho que es narrado por películas y libros. Ricardo aproxima la explotación esclavizadora de los indígenas a la violencia contra las mujeres. Es significativo que dos jóvenes mujeres indiquen la importancia de la temática de género al mirar un contenido sustantivo generalmente abordado bajo la perspectiva masculina, aún más cuando un joven hombre también indica que eso ocurrión ${ }^{35}$.

\section{Conquista y colonización de América}

Quince veces los jóvenes investigados citaron la conquista y colonización de América como una posibilidad de mirar la experiencia histórica del encuentro de los indígenas con los europeos. Esta categoría tiene una relación directa con la cultura escolar ${ }^{36}$ de los estudiantes, pues aparece mucho en las clases de historia narradas por los profesores y abordadas en los libros de texto

${ }^{35}$ Estos datos empíricos van al encuentro de los investigados por Lucas Pydd Nechi al indicar que el posicionamiento en relación con la dignidad humana relativa a las relaciones de género a lo largo del tiempo es controvertido, y no establece unanimidad entre los jóvenes investigados. En cuanto a las especificidades de grupos humanos en relación de opresión, la opinión de los jóvenes nos parece indicar que son fruto de diferencias culturales. En lo que se refiere a las relaciones de género, las mujeres y la población LGBT, en el Reino Unido, son considerados grupos que pasaron por una evolución positiva con el paso del tiempo, hecho que no se reconoce en la opinión de los jóvenes brasileños. Algunos afirman discrepar fuertemente, lo que posiblemente remite a experiencias negativas personales. Ver Lucas Pydd Nechi, O novo humanismo como princípio de sentido da didática da história: reflexões a partir da consciência histórica de jovens ingleses e brasileiros (Curitiba: UFPR, 2017).

36 Siguiendo las ideas de Jean-Claude Forquin, entiendo como „cultura escolar“ el conjunto de saberes que, una vez sistematizado, didactizado, compone la base de conocimientos sobre la que trabajan profesores y estudiantes. Se presupone, en esta concepción, una selección previa de elementos de la cultura humana, científica o popular, erudita o de masas. Ver Jean-Claude Forquin, Escola e cultura: as bases sociais e epistemológicas do conhecimento escolar (Porto Alegre: Artes Médicas, 1993). 
de historia. La referencia a la llegada de los españoles, portugueses y otros europeos a América y los datos empíricos y la idea del descubrimiento de Brasil son muy destacados por estos sujetos.

La conquista de América; la esclavización de los indígenas. (Sergei - 17 años Várzea Grande).

La versión A: la llegada de los españoles a América; la versión B: colocaron a los indios para el trabajo esclavo. (Judith - 16 años - Várzea Grande).

El comienzo de la colonización de América y el encuentro con los indígenas. (Taibo - 16 años - Várzea Grande).

Los jóvenes destacan que la idea de conquista de América por los europeos es una concepción sólida en lo que se refiere a la relación del encuentro entre indígenas y europeos. Sergei y Judith vinculan esa experiencia de la conquista directamente con la esclavización de los indígenas, mientras que Taibo indica que este encuentro está vinculado al proceso de colonización del continente por los europeos. Verifico aquí como el concepto histórico de conquista de América, para esos jóvenes, está directamente relacionado con la dimensión de la explotación y sufrimiento humanos ${ }^{37}$.

La conquista de América y el descubrimiento de Brasil.(Diego - 17 años - Várzea Grande).

Fue la llegada de los portugueses en Brasil y con los indígenas. (Oscar - 16 años - Várzea Grande).

Que los españoles y portugueses fueron los grandes héroes del descubrimiento y exploración de las tierras americanas. Y los franceses siguieron también, así como Holanda e Inglaterra. (Paco - 17 años - Várzea Grande).

Tres estudiantes destacaron la participación de los portugueses en el proceso de conquista de América. Diego apuntó la idea de descubrimiento de Brasil con una de las experiencias vinculadas a la conquista de América. Es posible que ese joven no perciba la diferencia entre los conceptos de

${ }^{37}$ Rüsen, Cultura faz sentido, 296. 
conquista, que puede explicitar la dimensión violenta de ese proceso histórico, y descubrimiento de Brasil que puede generar una especie de neutralización y ocultamiento (principalmente de la historia indígena) de esa experiencia histórica. Paco defiende una concepción basada en la conciencia tradicional histórica y ejemplar ${ }^{38}$ para argumentar que los españoles, portugueses, seguidos por los holandeses, franceses e ingleses eran "grandes héroes" y exploradores de las "tierras americanas", idea que pertenece a la tradición de la cultura escolar de las clases de historia y, al mismo tiempo, se relaciona con los ideales de que son ejemplos a seguir como una historia maestra de la vida.

\section{Conflictos y guerras}

Conflictos y guerras fueron citados nueve veces por los jóvenes tal como lo expresan tres de ellos:

Guerra. Hasta hoy tenemos conflictos entre los estados. (Edward - 16 años Várzea Grande).

La guerra de los indios y los europeos, porque es muy contada en libros, entretenimiento, etc (Rocío - 17 años - Várzea Grande).

Realmente sucedieron laspeleas entre ellos, el uso de la mano de obra de los indios. (Lupe - 16 años - Várzea Grande).

Edward y Rocío entienden que la guerra es una experiencia del pasado presente en el encuentro entre indígenas y europeos. Para el primero, la guerra está vinculada al conflicto entre estados; ya para Rocío, el conflicto entre indios y europeos ocurrió porque fue representado por libros y por el entretenimiento mediático. Lupe entiende que los conflictos realmente ocurrieron y tenían relación con la explotación de la mano de obra indígena.

Entiendo que dos formas de percepción están presentes cuando abordamos las situaciones del pasado relativas al encuentro entre indígenas y europeos al enfrentar los dos cómics: 1) la dimensión del reconocimiento por parte de los jóvenes estudiantes que la explotación del trabajo y la violencia contra las mujeres indígenas está vinculada a la dimensión identitaria de los jóvenes investigados, pues han hecho hincapié en esas formas de sufrimiento humano; 2) la fuerza de la tradición de la cultura escolar en las clases de historia, pues

${ }^{38}$ Rüsen, História viva, 48-55. 
esa forma de pensar y didactizar la historia es un instrumento de selección que atraviesa la conciencia histórica de los jóvenes investigados, principalmente debido a la presencia de las ideas del protagonismo del europeo frente a los indígenas y de conceptos como descubrimiento o conquista que son poco debatidos por esos sujetos. Opté por analizar, bajo la óptica de la interpretación histórica y de la orientación histórica, las respuestas en las que los jóvenes justifican el porqué de sus elecciones y creo que las concepciones que presento podrían ser intercambiables entre esas operaciones mentales.

\section{La interpretación histórica}

Consideré como integrantes de la operación mental de la interpretación histórica las respuestas en las que los jóvenes justificaban las experiencias que realmente sucedieron a partir de las categorías de la verdad histórica y del cambio histórico, además de las ideas sustantivas relativas a la política, al trabajo y la riqueza.

\section{Relación con la verdad histórica}

Esta categoría fue movilizada por cinco jóvenes cuando se les preguntó sobre cuáles son las situaciones del pasado que consideraban verdaderas:

Las versiones 'A y B', porque lo que cuenta allírealmente sucedió. Y eso es un hecho. (Flora - 16 años - Várzea Grande).

Las versiones Ay B. Porque tuvieron muchas guerras con disputas por territorios, mucha esclavitud, etc. Y lo que está mostrando es lo que realmente sucedió. (Susan - 16 años - Várzea Grande).

[Laversión] A.Porque es más realista y habla sobre las conquistas que los europeos tuvieron en aquella época. (Frida - 16 años - Várzea Grande).

Yo sé más la parte del lado B, sí sucedió. (Janis - 16 años - Várzea Grande).

Cuatro jóvenes vincularon la plausibilidad de la ocurrencia del encuentro entre indígenas y europeos a partir de las versiones de los cómics A y B. Flora, Frida y Susan entienden que los cómics cuentan, hablan o muestran sobre lo que realmente sucedió. Flora y Susan comprenden que ambas versiones narran la verdad sobre lo que sucedió (Flora), y sobre las guerras, disputas territoriales 
y esclavitud (Susan). Frida defiende que las conquistas europeas del pasado fueron narradas de modo más realista por la versión $\mathrm{A}^{39}$, mientras Janis, que lo que se narra en la versión $\mathrm{B}^{40}$ ocurrió afirmativamente.

En mi concepto, creo que esas situaciones sucedieron realmente, pues hubo la pelea entre los europeos, la llegada de los inmigrantes y los pueblos indígenas. (Anita - 17 años - Várzea Grande).

Anita defiende que en su concepción esas situaciones sucedieron realmente, incluso al construir la inferencia de que los europeos de la época de la conquista de América eran inmigrantes; concepto que sólo posteriormente será construido por la historiografía para designar otra experiencia histórica ocurrida en el continente americano en otro momento histórico. Se hace evidente en las respuestas de estos estudiantes la concepción de una verdad única e indiscutible presentada por los cómics. Según Bodo von Borries ${ }^{41}$, hay necesidad de desarrollar más el concepto de multiperspectividad en las clases de historia para que haya una disminución del poder de las narrativas monológicas vehiculadas por los libros de texto de historia y a veces reproducidas por maestros y estudiantes.

\section{Relación con el cambio histórico}

Una joven estudiante abordó el cambio histórico como una categoría fundamental para comprender la experiencia del encuentro entre europeos e indígenas en el pasado.

Las 13 colonias y la lucha contra los aztecas y los incas. Porque si no hubieran creado las 13 colonias y no hubieran derrotado a los incas tal vez los países que conocemos, México y Perú, no serían como son hoy. (Elisa - 16 años - Várzea Grande).

Para Elisa, las violentas experiencias históricas de la colonización inglesa de América del Norte y de la conquista militar española en América Latina

${ }^{39}$ Castro y Zalla, História Geral.

${ }^{40}$ Altan, Colombo.

${ }^{41}$ Bodo von Borries, "Lidando com histórias difíceis", en Jovens e consciência histórica, coordinado por Maria Auxiliadora Schmidt, Marcelo Fronza y Lucas Pydd Nechi (Curitiba: W.A. Editores, 2016), 32-54. 
generaron los actuales estados nacionales de esas regiones del planeta, tales como los Estados Unidos de América (implícitos en la respuesta) y México y Perú. La dimensión de la transformación histórica está presente en su argumentación, aunque este cambio haya sido constituido por medio del sufrimiento humano por la guerra y la colonización. Es posible detectar una comprensión histórica ontogenética de esa joven cuando percibe cómo el cambio es generado por el sufrimiento ${ }^{42}$.

\section{Relación con la política}

Dos jóvenes procuraron justificar sus respuestas por medio de una interpretación política del encuentro entre indígenas y europeos.

Guerra. Hasta hoy tenemos conflictos entre los estados. (Edward - 16 años Várzea Grande).

Las versiones A y B.Porque tuvieron muchas guerras con disputas por territorios, mucha esclavitud, etc. Y lo que está mostrando es lo que realmente sucedió." (Susan - 16 años - Várzea Grande).

Edward considera que la guerra y los conflictos entre los Estados naciones son elementos que marcaron la experiencia histórica de América. De la misma forma, Susan también percibió que la dimensión política de la cultura histórica ${ }^{43}$ expresada en los cómics demarca una verdad sobre lo que realmente ocurrió en ese proceso de guerras, disputas territoriales y la esclavitud en el continente.

\section{Relación con el trabajo}

Una joven justificó como posibilidad interpretativa una situación del pasado vinculada a la explotación con relación al trabajo:

La explotación de los indígenas, pues los europeos querían su fuerza de trabajo. (Christiane-16 años - Várzea Grande).

Christiane afirma que la explotación se dio debido al deseo de los europeos en dominar la fuerza de trabajo indígena. Esta interpretación se acerca a las citas

\footnotetext{
${ }^{42}$ Jörn Rüsen, "Formando a consciência histórica - para uma didática humanista da história", en Humanismo e didática da história (Jörn Rüsen), coordinado por Maria Auxiliadora Schmidt, Isabel Barca, Marcelo Fronza y Lucas Pydd Nechi (Curitiba: W. A. Editores, 2015), 19-42.

${ }^{43}$ Rüsen, “¿Qué es la cultura histórica?", 13, 18-20.
} 
de la mayoría de los jóvenes que afirman que la esclavización de los indígenas fue un marco del proceso de colonización de América.

\section{Relación con la riqueza}

La categoría de la relación con la riqueza fue la interpretación defendida por una joven en esa investigación.

Que losespañoles y los portuguesesfueron los grandes exploradoresdelas Américas. $Y$ después de 30 años, Brasil ha sido abandonado por los portugueses, ya que estaban más interesados en la riqueza [de las Indias] (Monna - 17 años Várzea Grande).

Monna entiende que después de la llegada de la explotación española y portuguesa en América, Brasil fue abandonado porque los portugueses estaban interesados en las riquezas de Oriente. La relación entre Portugal y las Indias era también un fenómeno importante para entender la colonización de Brasil. Se percibe que el proceso histórico de la explotación europea en Brasil no ocurrió de forma continua, pues la búsqueda por la riqueza era el principal objetivo de la metrópoli. Esa interpretación es conectada a la cultura escolar, pues en los libros de texto de historia la idea de abandono de Brasil tras el fracaso de las capitanías hereditarias es muy fuerte, a pesar del hecho de que los convictos y colonos portugueses continuaban llegando en la América portuguesa.

\section{La orientación histórica}

Con respecto a la operación mental de la orientación histórica, categoricé las respuestas de los jóvenes a partir de tres formas: la relación estética con el pasado, la relación con la interculturalidad y la relación con el aprendizaje histórico.

\section{Relación estética con el pasado}

La categoría relativa a la relación estética con el pasado fue la más abordada por los jóvenes en lo que se refiere a la forma en que la situación del encuentro entre indígenas y europeos se dio como un elemento de orientación temporal por medio de los cómics: 
La situación de la matanza de los indígenas y la explotación de sus mujeresporque en todos los libros y películas de esa época siempre destacan ese acontecimiento. (Dolores - 17 años - Várzea Grande).

La guerra de los indios y los europeos, porque es muy contada en libros, entretenimiento, etc. (Rocio - 17 años - Várzea Grande).

Robo, muertes. Por la escena da para ver. (Mildred - 16 años - Várzea Grande).

No. Es historia" (Julio - 18 años - Várzea Grande).

Cuatro jóvenes estudiantes entienden que la experiencia histórica del conflicto entre indígenas y europeos durante la conquista de América está directamente relacionada con la dimensión estética de la cultura histórica ${ }^{44}$ transmitida por los cómics. Dolores y Rocío dicen que libros, películas y otras formas de entretenimiento narran con veracidad el genocidio contra los indígenas, la violencia contra las mujeres y la guerra. Mildred indica que las escenas narradas en los comics se refieren a robos y muertes. Para estas jóvenes, la dimensión estética que vivifica la experiencia del sufrimiento humano tiene fuerza de verdad. Sólo Julio entiende que las versiones de cómics presentadas narran solamente historias ficticias, que no se refieren a las situaciones que realmente sucedieron en el pasado.

Luego en losprimeroscómics (A) retratan sobrelo que ocurrió en el Descubrimiento. Al final, en los cómics (A) es lo que está retratado más y el Descubrimiento de Brasil. (Concha - 16 años - Várzea Grande).

[Laversión] A.Porque es más realista y habla sobre las conquistas que los europeos tuvieron en aquella época. (Frida - 16 años - Várzea Grande).

Las versiones A y B. Porque tuvieron muchas guerras con disputas por territorios, mucha esclavitud, etc. Y lo que está mostrando es lo que realmente sucedió. (Susan - 16 años - Várzea Grande).

Tres jóvenes estudiantes informan a qué estilo estético están vinculados los cómics. Para ellas, el realismo es la forma estética que moviliza la narrativa sobre

${ }^{44}$ Rüsen, “¿Qué es la cultura histórica?", 13, 15-19. 
la conquista de América. Para Concha, la versión $\mathrm{A}^{45}$ retrata los acontecimientos relativos al "Descubrimiento de Brasil". Para Frida, incluso las conversaciones presentes en esos artefactos de la cultura histórica se refieren a la forma realista de narrar aquel pasado. Susan también considera el realismo como una forma de leer el pasado al afirmar que las versiones $\mathrm{A} \mathrm{y}^{4}{ }^{46}$ muestran lo que realmente sucedió en los primeros encuentros entre europeos e indígenas.

\section{Relación con la interculturalidad}

Dos jóvenes movilizaron la categoría de la relación con la interculturalidad para orientarse temporalmente cuando justificaron las situaciones del pasado:

Que los indios fueron explotados porque hasta hoy tiene cierta discriminación con ellos. (Olga - 16 años - Várzea Grande).

Según Olga, la discriminación que los indios aún sufren en el mundo contemporáneo está directamente ligada a la explotación a la que fueron sometidos por los europeos. Para esta joven, el prejuicio contra esos seres humanos es una marca o una evidencia del sufrimiento que padecieron durante el proceso de colonización de las Américas y la formación de los Estados nacionales en el continente. Esta joven fue la única estudiante, en el marco de esta investigación, que apuntó el prejuicio y la discriminación como un elemento de las formas de orientación temporal identitarias que aún marcan a las sociedades latinoamericanas expresando su dimensión conservadora e incluso reaccionaria. Este elemento etnocéntrico aparece en las respuestas de esa y otros jóvenes en otras cuestiones de ese instrumento de investigación ${ }^{47}$.

Creo que realmente hubo un choque de culturas en el primer encuentro entre europeos e indígenas. También creo que los españoles/portugueses han explorado realmente los indiosnativos de América... (Philip - 16 años - Várzea Grande).

Philip defiende que hubo un choque cultural en los primeros encuentros entre indígenas y europeos en América. Para Jörn Rüsen ${ }^{48}$, el reconocimiento

\footnotetext{
${ }^{45}$ Castro y Zalla, História Geral.

${ }^{46}$ Altan, Colombo.

${ }^{47}$ Estas otras cuestiones se abordarán en otras investigaciones.

${ }^{48}$ Rüsen, Cultura faz sentido, 296.
} 
del conflicto cultural es uno de los primeros pasos que capta la construcción de una interculturalidad igualitaria entre los seres humanos, porque los intercambios se modifican en la relación mutua entre los diferentes. Para ese joven, el reconocimiento de la violencia colonial contra los indígenas es un paso hacia la construcción de una relación igual entre indígenas y no indígenas.

\section{Relación con el aprendizaje histórico}

Una joven entendió como relevante para la orientación temporal proporcionada por esa experiencia del pasado la relación con el aprendizaje histórico.

En laspartes que hablan de Napoleón Bonaparte, Cristóbal Colón, Hernán Cortés. Porque son los personajes que he escuchado muchas historias de ellos. (Benina - 16 años - Várzea Grande).

Para Benina, los cómics revelan su fuerza de orientación temporal cuando se remiten a los nombres propios de Napoleón Bonaparte, Cristóbal Colón y Hernán Cortés, pues ella ya oyó hablar de ellos en muchas historias. Esa dimensión narrativa del aprendizaje histórico es muy evidente en la respuesta de esta joven. Es importante destacar que esa dimensión del aprendizaje fue movilizada en la cultura escolar por medio de nombres propios desde una perspectiva de la historia de los grandes héroes de la humanidad. Para Benina, es exactamente esa identificación la que da veracidad a los cómics.

Es importante destacar que, en esta cuestión relativa a las situaciones del pasado, que los jóvenes citan como verdaderas, hubo predominancia de eventos pasados narrados directamente por los cómics, pues raramente aparecieron interpretaciones históricas construidas en el contexto de la producción de esos artefactos culturales (décadas de 1970 y 1980). Sin embargo, los jóvenes que citaron las situaciones de violencia contra las mujeres, la situación de la discriminación e incluso la esclavitud están movilizando temporalmente la lectura del pasado del encuentro entre indígenas y europeos durante la conquista de América desde las carencias de orientación temporal de la praxis social contemporánea en Brasil ${ }^{49}$.

La segunda cuestión argumentativa busca comprender las ideas históricas que estos jóvenes estudiantes operan cuando se enfrentan al principio de

${ }^{49}$ Jörn Rüsen, "Formando a consciência histórica - para uma didática humanista da história", en Humanismo e didática da história (Jörn Rüsen), coordinado por Maria Auxiliadora Schmidt, Isabel Barca, Marcelo Fronza y Lucas Pydd Nechi (Curitiba: W. A. Editores, 2015), p. 19-42. 
la interculturalidad. La cuestión fue fundamentada en la teoría del nuevo humanismo vinculada a los conceptos de intersubjetividad e interculturalidad ${ }^{50}$. Con ella busco comprender si los jóvenes estudiantes de enseñanza media de Várzea Grande, en Mato Grosso, Brasil, entienden, o no, si los conflictos son posibilidades de comunicación intercultural que se hacen valer. Por lo tanto, la cuestión es: Considerando las narrativas de lasversiones $A y$ B, ¿cómo usted entiende que deben ser las relaciones con los indígenas de Brasil y de América? ¿Por qué?

La cuestión de cómo los jóvenes comprenden que deben ser nuestras relaciones con los indígenas en Brasil y en América, a partir de las narraciones de Julierme Castro (versión A) y Altan (versión B), llevó a la condensación de datos en el cuadro 2 que expresa cómo los sujetos movilizaron categorías cuando justificaron sus respuestas a partir de las dos premisas problemáticas, el etnocentrismo y el relativismo cultural, discutidas por el nuevo humanismo de Rüsen y también por medio de la premisa del principio del reconocimiento mutuo de la interculturalidad ${ }^{51}$ : (Tabla 02)

Tabla 2 - Nuestra relación con los indígenas en Brasil y en América

\begin{tabular}{|c|c|c|}
\hline Premisas & Categorías movilizadoras & $\begin{array}{l}\text { N.. de } \\
\text { jóvenes }\end{array}$ \\
\hline \multirow{2}{*}{ Etnocentrismo } & $\begin{array}{l}\text { Percepción de la explotación y } \\
\text { violencia contra los indígenas }\end{array}$ & 14 \\
\hline & Prejuicio contra los indígenas & 1 \\
\hline \multirow{2}{*}{ Relativismo cultural } & $\begin{array}{l}\text { Relaciones de neutralidad } \\
\text { de los valores morales }\end{array}$ & 1 \\
\hline & $\begin{array}{l}\text { Relaciones de simultaneidad } \\
\text { entre evolución y tradición }\end{array}$ & 1 \\
\hline Interculturalidad & Relaciones de reconocimiento & 3 \\
\hline \multicolumn{2}{|c|}{ No respondieron } & 17 \\
\hline \multicolumn{2}{|c|}{ Respuestas incomprensibles } & 2 \\
\hline
\end{tabular}

Fuente: elaboración del autor, 2018.

${ }^{50}$ Jörn Rüsen, Culturafaz sentido: orientações entre o ontem e o amanhã, (Petrópolis: Vozes, 2014), p. 295-296. Jörn Rüsen, "Formando a consciência histórica - para uma didática humanista da história”, en Humanismo e didática da história (Jörn Rüsen), coordinado por Maria Auxiliadora Schmidt, Isabel Barca, Marcelo Fronza y Lucas Pydd Nechi (Curitiba: W. A. Editores, 2015), p. $19-42$.

${ }^{51}$ Rüsen, Cultura faz sentido, 296-297. 
Antes de analizar las categorías, es importante subrayar que muchos jóvenes no se sintieron a gusto, o no supieron responder esa cuestión; tal es la dimensión del sufrimiento y el olvido que la temática del sufrimiento indígena está demarcada en la cultura histórica brasileña y mato-grossense. De los treinta y nueve jóvenes investigados, diecisiete de ellos optaron por no responder, o no supieron responder, la cuestión; aunque la mayoría de ellos sean descendientes de indígenas y/o afrobrasileños y presenten fenotipos concordantes con esa descendencia.

\section{Etnocentrismo}

La premisa problemática más abordada por los jóvenes estudiantes cuando enfrentaron la cuestión de nuestra relación con los indígenas en Brasil y en América fue, para quince de esos sujetos, el etnocentrismo. La categoría mayoritaria con relación al etnocentrismo fue el reconocimiento de que existió la explotación y la violencia contra los indígenas.

\section{Percepción de la explotación y violencia contra los indígenas}

Catorce jóvenes asumieron la percepción de la explotación y la violencia contra los indígenas como una premisa que sostiene el etnocentrismo brasileño y latinoamericano narrado por los dos cómics. Como la cuestión fue de difícil respuesta para los jóvenes, presentaré las argumentaciones según el grado de énfasis de los investigados con relación a su posicionamiento contra el etnocentrismo.

Ellos tenían que saber dividir las tierras sin avidez y sin codicia por quées pecado. 'Sea más humilde'. (Edward - 16 años - Várzea Grande).

Fue una relación de explotación de los indígenas y de la forma de conversar. (Oscar - 16 años - Várzea Grande).

Una relación muy agresiva. Esa es mi opinión. (Rocío - 17 años - Várzea Grande).

La relación, en mi opinión, era muy complicada, pues tenía muchos conflictos" (Susan - 16 años - Várzea Grande).

Una relación conflictiva. (Bosco - 17 años - Várzea Grande). 
Conturbado. (Christiane - 16 años - Várzea Grande).

Estos seis jóvenes expresaron una clara indignación en relación a las historias de sufrimiento narradas por los cómics. Edward expresa claramente su posición contra la "avidez" y la "codicia" de los europeos en relación con las tierras indígenas. Para ese joven, las tierras deberían ser divididas y no robadas. Se nota también que la dimensión religiosa de la cultura histórica ${ }^{52}$ de este joven está muy presente en su respuesta, pues la humildad es un valor moral cristiano fundamental para combatir el pecado de la codicia. Oscar también subrayó que lo que ocurrió fue una relación de explotación de los indígenas por los europeos y que eso está explícito en la forma como ellos se comunicaban. Rocío, así como Susan, Bosco y Christiane, subrayan sus posiciones al afirmar que hubo agresividad, conflicto, complicación y conturbación en la relación que los europeos tuvieron con los indígenas.

Sin embargo, hay jóvenes que buscaron mitigar la dureza de esa relación cultural agresiva y conturbada.

Las relaciones no son muy buenas a causa de las intrigas y conflictos que tenía. (Frida - 16 años - Várzea Grande).

Una relación no muy agradable ni tranquila,pueslosindígenas fueron esclavizados. (Flora - 16 años - Várzea Grande).

Deben ser malas. Debe tener guerra. (Mildred - 16 años - Várzea Grande).

Las relaciones no eran muy buenas, ya que los portugueses no consideraban a los indígenas como personas, pero sí como animales. (Judith - 16 años - Várzea Grande).

La relación entre los indígenas y de América de antaño era un poco difícil entre ellos. Entonces, la convivencia entre ellos no era muy buena. (Lupe - 16 años - Várzea Grande).

Estos cinco jóvenes estudiantes trataron de suavizar el dolor que esa experiencia del pasado trae a nuestra cultura histórica contemporánea con expresiones que intentan apaciguar la dimensión conflictiva de la conquista de América, que ellos mismos reconocen. Frida, Flora y Mildred sospechan

${ }^{52}$ Rüsen, Cultura faz sentido, 315-319. 
que las relaciones con los indígenas no fueron tan buenas debido a conflictos, intrigas, guerras y esclavitud. Estas jóvenes reconocen el sufrimiento de estos sujetos y perciben que tal vez no fuera tan bueno convivir con los europeos. Judith cree que las relaciones no eran muy buenas debido a los prejuicios raciales que los portugueses tenían sobre los indígenas porque, para ella, estos europeos consideraban a los nativos como animales en lugar de seres humanos. Lupe comprende que la relación entre los conquistadores y dominados fue "un poco difícil", porque no había una convivencia muy buena entre esos sujetos. Se siente cierto intento de distanciamiento de esos jóvenes con relación al sufrimiento humano; sin embargo, ni deslegitimándolos ni tan poco desvalorizándolos. Hay una relación de incomodidad que esos jóvenes sienten en relación con la temática de la explotación indígena corroborando con la ausencia de respuestas a la cuestión indicada.

Por las imágenes, los indios eran esclavizados por los europeos. Trabajaban como siervos haciendo todos los deseos de los europeos. (Paco - 17 años - Várzea Grande).

Porque él cuenta la historia del descubrimiento y, en las historias, tiene la parte de los indígenas de Brasil y de América. (Concha - 16 años - Várzea Grande).

Paco y Concha se diferencian de los otros jóvenes en sus respuestas al remitir a los cómics el suministro de indicios y evidencias sobre el sufrimiento en el pasado. Para Paco, la esclavización de los indígenas por los europeos, que los hacían trabajar como "siervos haciendo todos los deseos", es un indicio de cómo fueron esas relaciones en el pasado. Concha entiende que esa relación con el pasado es neutra, pues los cómics sólo narran la historia del descubrimiento de Brasil y de América.

Creo que debería haber cierta rivalidad entre las tribus/imperios indígenas que había en América. (Phillip - 16 años - Várzea Grande).

Este joven también presenta una respuesta diferenciada en relación al etnocentrismo presente en la cultura histórica. Philip indica que había rivalidad entre las aldeas e imperios indios americanos demostrando que conoce la complejidad del proceso histórico ocurrido en este continente. Por lo tanto, para él, incluso los indígenas actuaban de manera etnocéntrica. Es importante percibir que la memoria de victimización de los pueblos indígenas puede llevar 
al olvido de las relaciones históricas de conflictos etnocéntricos que existían y existen entre ellos. El reconocimiento mutuo pasa por la aceptación de que hay choques culturales incluso entre los pueblos contrahegemónicos. Este es un paso fundamental para la construcción de la interculturalidad ${ }^{53}$.

\section{Prejuicio contra los indígenas}

He encontrado sólo una respuesta que indique alguna afirmación de prejuicio contra los indígenas:

Los indígenas tienen una relación poco saludable, porque ellos realmente no se mezclan con los otros pueblos. (Olga - 16 años - Várzea Grande).

Olga se posicionó claramente contra la actitud de muchos indígenas de "no mezclarse con otros pueblos" y aún defiende un juicio de valor al considerarla "poco saludable". Es posible que en esa argumentación esa joven haya olvidado las humillaciones que los indígenas sufrieron en el contacto con los europeos. Lo curioso en esa respuesta es que en otras cuestiones esa joven es la única que claramente indica que la discriminación racial contra los indígenas, en el pasado y en el presente, es una carencia de orientación temporal de la cultura histórica contemporánea en Brasil. Las argumentaciones de esta joven hacen pensar en la contradicción que los latinoamericanos, y en especial los brasileños, tienen en relación al racismo y, principalmente, en asumir el propio prejuicio racial para que pueda ser combatido y superado. Esta es también una forma muy evidente, para algunos jóvenes, de cómo el sufrimiento humano se expresa en la cultura histórica brasileña.

\section{Relativismo cultural}

Las categorías presentes en las respuestas de los jóvenes que aparentan presentar un perfil pautado en la premisa problemática del relativismo cultural son las siguientes:

\section{Relaciones de neutralidad de los valores morales}

Una joven presentó una relativización moral de la relación de la violencia que existió en el pasado americano.

${ }^{53}$ Rüsen, 295-296. 
Creo que la relación debe ser amenizada. Ni buena ni mala, porque los dos lados entienden el sufrimiento de sus tribus. (Dolores - 17 años - Várzea Grande).

Dolores defiende que la relación conflictiva entre indígenas y europeos en Brasil y en América deba ser apaciguada. Ella entiende que esa relación no es ni buena ni mala, pues tanto los europeos como los indígenas comprenden mutuamente sus sufrimientos. Ella propone una relativización pautada en la neutralidad de los valores morales en el modo en que debemos afrontar nuestras relaciones con los indígenas. Para ello, Dolores presupone la premisa de que ambos lados de los conflictos reconocen el sufrimiento del otro. Si se superó la idea de la neutralidad, tal vez esa relativización pautada en el reconocimiento mutuo podría ser categorizada como un paso en la relación para una interculturalidad igualitaria. Considero que esta joven tiene un deseo de que el conflicto con los indígenas sea suavizado por comprender que esa lucha por reconocimiento genera dolor para todos los involucrados, pero entra en contradicción cuando ese proceso deba ser realizado de forma neutra.

\section{Relaciones de simultaneidad entre evolución y tradición}

Una joven expresó su posición en relación con la temática indígena por medio de relaciones de simultaneidad entre evolución cultural y tradición.

Las relaciones entre los indios de Brasil y América tal vez sean diferentes, porque muchos indios evolucionaron. Otros tal vez continuaron la tradición de sus antepasados. (Elisa - 16 años - Várzea Grande).

Según Elisa, nuestra relación con los indígenas debe ser pensada en la forma de un proceso histórico y en la especificidad propia de la experiencia histórica brasileña con relación a la experiencia americana. Para ella, el criterio que demarca esa complejidad es que algunas sociedades indígenas evolucionaron y otras continuaron las tradiciones de sus antepasados. Si interpretamos esa respuesta a la luz de otras cuestiones respondidas por esa joven, tal vez ella entienda por evolución a las sociedades indígenas que se han convertido en Estados antes o Estados nación después del proceso de colonización europea: México y Perú. Mientras tanto, en Brasil, el Estado nación se formó y los indígenas, en la percepción de ella, permanecen siguiendo las tradiciones ancestrales. Es posible que más que un relativismo cultural, Elisa esté defendiendo una relatividad intrínseca en la formación histórica de las 
sociedades. Sin embargo, como no se posicionó claramente con relación a la temática del sufrimiento indígena, su respuesta no nos da base para interpretar cuál es la orientación temporal defendida por esa joven.

\section{La interculturalidad}

La premisa del principio de la interculturalidad como comprensión empática respecto al otro se reveló presente en una categoría:

\section{Relaciones de reconocimiento}

Tres jóvenes se expresaron por medio de esta categoría al entender el reconocimiento entre los sujetos como la base de las relaciones con los indígenas.

Una buena relación. (Julio - 18 años - Várzea Grande).

Una relación normal sin prejuicios, porque los indígenas también son seres humanos. (Apollinaria - 17 años - Várzea Grande).

Yo creo que la cultura indígena debe ser conservada, pues queriendo o no es parte de nuestra historia, es parte de nuestro pasado. (Taibo - 16 años - Várzea Grande).

Para Julio, las relaciones con los pueblos indígenas deben ser buenas sin mayores explicaciones. Sin embargo, según Apollinaria, una relación "normal" con los indígenas debe ser sin prejuicios por el hecho de que esos sujetos pura y simplemente son seres humanos y por eso deben ser respetados. La idea que rige la comprensión de esta joven es el principio de la humanidad y de la reciprocidad entre los sujetos. Esto porque, para ella, los indígenas "también son seres humanos", lo que lleva al reconocimiento de que las diversas perspectivas tienen una relación mutua en relación a la otra. En ese sentido, Taibo comprende que la conservación de la cultura indígena en Brasil y en América es prioritaria porque, independiente de la voluntad de cada sujeto, "forma parte de nuestra historia, forma parte de nuestro pasado".

Estas respuestas entienden que la intersubjetividad la internaliza, en los estudiantes, el principio de la humanidad en sus propias biografías en relación con las de los otros en el tiempo y en el espacio ${ }^{54}$. Comprenden como posibles

${ }^{54}$ Rüsen, Aprendizagem histórica, 107-108. 
las oportunidades de comunicación intercultural, pues las culturas aprenden unas de otras y se modifican en la relación mutua, se interpenetran, se delimitan unas con las otras, se combaten ${ }^{55}$.

\section{Consideraciones finales}

Como conclusión es posible verificar si estos jóvenes estudiantes entienden, a partir de la confrontación narrativa de esas interpretaciones históricas, que algunos de los elementos fundamentales de esos artefactos de la cultura histórica, considerando las experiencias investigativas explicitadas, buscan seguir como criterio los principios de una cognición histórica situada en la epistemología de la Historia y en la teoría de la conciencia histórica. Eso porque demarcan parámetros para la construcción de la interculturalidad en los procesos de formación docente en Historia.

He constatado dos formas de percepción histórica presentes cuando abordamos las situaciones del pasado relativas al encuentro entre indígenas y europeos cuando se enfrentan a los dos cómics: 1) la dimensión del reconocimiento por parte de los jóvenes estudiantes que la explotación del trabajo y la violencia contra las mujeres indígenas están vinculadas a la dimensión identitaria de los jóvenes investigados, pues han hecho hincapié en esas formas de sufrimiento humano; 2) la fuerza de la tradición de la cultura escolar en las clases de historia, pues esa forma de pensar y didactizar la historia es un instrumento de selección que atraviesa la conciencia histórica de los jóvenes investigados, principalmente debido a la presencia de las ideas del protagonismo del europeo frente a los indígenas y de conceptos, como descubrimiento o conquista, que son poco debatidos por esos sujetos. La dimensión estética de la cultura histórica de esos jóvenes brasileños dominó la forma en que leen en los cómics la relación de explotación y conflicto entre europeos e indígenas durante la conquista de América.

Al investigar cómo debería ser, para los jóvenes investigados, nuestra relación con los indígenas de Brasil y de América, la premisa problemática del etnocentrismo fue citada por la gran mayoría de ellos, aunque implícitamente se posicionaran contra ella. La premisa problemática del relativismo cultural también apareció, para dos jóvenes, expresada tanto por la creencia en la neutralidad de los valores morales y por la defensa de la relatividad de las diferentes experiencias históricas de la formación cultural de los indígenas. Sin embargo, la premisa humanista pautada en la relación mutua también fue

${ }^{55}$ Rüsen, Cultura faz sentido, 296. 
destacada con énfasis por tres jóvenes. Esto permite la constatación de que, a pesar de minoritaria entre los investigados, la concepción humanista de la interculturalidad también está presente en la conciencia histórica de los jóvenes de los suburbios de Cuiabá, incluso conviviendo diariamente con la violencia urbana típica de las grandes ciudades brasileñas.

Se verificó que las operaciones mentales de la conciencia histórica sí expresan las diferentes formas de abordaje en relación con la interculturalidad de las experiencias históricas, con la controversia de las interpretaciones y la pluralidad de formas de orientación de sentido en el tiempo que constituyen las relaciones intersubjetivas e interculturales en el proceso de la formación histórica de la humanidad en la que el aprendizaje histórico está íntimamente ligado. Esta conciencia posibilita la construcción de criterios humanistas e intersubjetivos que aporten principios para la formación de una identidad histórica basada en la interculturalidad, es decir, en el reconocimiento mutuo de las diferencias regidas por una alteridad igualitaria.

\section{Referencias bibliográficas}

\section{Fuentes secundarias}

Altan, Francesco Tulio. Colombo. Porto Alegre/São Paulo: LP\&M Editores, 1989.

Borries, Bodo von. "Lidando com histórias difíceis". En Jovens e consciência histórica, compilado por M. A. Schmidt, M. Fronza, L. P. Nechi, 32-54. Curitiba: W. A. Editores, 2016.

Borries, Bodo von. ,"Multiperspectividade: pretensão utópica ou fundamento factível da aprendizagem histórica na europa?". En Jovens e consciência histórica, compilado por M. A. Schmidt, M. Fronza, L. P. Nechi, 79-102. Curitiba: W.A. Editores, 2016.

Castro, Julierme de Abreu y Rodolfo ZALLA. História Geral - História para a Escola Moderna. São Paulo: Ibep, 1971.

Dubet, François y Danilo Martuccelli. En la escuela: sociología de la experiencia escolar. Buenos Aires: Editorial Losada, 1998.

Forquin, Jean-Claude. Escola c cultura: as bases sociaise epistemológicas do conhecimento escolar. Porto Alegre: Artes Médicas, 1993.

Hobsbawm, Eric J. Era dos extremos: o breve século XX. São Paulo: Companhia das Letras, 1995.

Lee, Peter y Rosalyn Ashby. "Progression in Historical Understanding among Students Ages 7-14". En Knowing, Teaching and Learning History: National and International Perspectives, editado por Peter N. Stearns, Peter Seixas y Sam Wineburg, 199-222. New York: New York University Press, 2000. 
Lee, Peter. "Understanding History”. En Theorizing Historical Consciousness, editado por Peter Seixas, 129-164. Toronto/Buffalo/London: University of Toronto Press, 2006.

Lessard-Hébert, Michelle, Gabriel Goyette y Gérald Boutin. Investigação qualitativa: fundamentos e práticas. Lisboa: Instituto Piaget, 2005.

Monteiro, John M. Negros da terra: Índios e bandeirantes nas origens de São Paulo. São Paulo: Companhia das Letras, 1994.

Nechi, Lucas Pydd. O novo humanismo como princípio de sentido da didática da história: reflexões a partir da consciência histórica de jovens ingleses e brasileiros. Tese Doutorado em Educação, Universidade Federal do Paraná, UFPR,'Curitiba, 2017.

Rüsen, Jörn. “¿Qué es la cultura histórica?: Reflexiones sobre una nueva manera de abordar la historia." Cultura histórica.es, 1994. [Versión castellana inédita del texto original alemán en K. Füssmann, H. T. Grütter y J. Rüsen, eds. Historische Faszination. Geschichtskultur heute. Keulen, Weimar y Wenen: Böhlau, pp. 3-26], consultado el 01 de noviembre de 2010, http://www.culturahistorica.es/ruesen/ cultura_historica.pdf.

Rüsen, Jörn. A razão histórica: Teoria da história: os fundamentos da ciência histórica. Brasília: UnB, 2001.

Rüsen, Jörn. História viva: Teoria da História III: formas e funções do conhecimento histórico. Brasília: UnB, 2007.

Rüsen, Jörn. Reconstrução do passado: Teoria da História II: os princípios da pesquisa histórica. Brasília: UnB, 2007a.

Rüsen, Jörn. Aprendizagem histórica: Fundamentos e paradigmas. Curitiba: W. A. Editores, 2012.

Rüsen, Jörn. Cultura faz sentido: orientações entre o ontem e o amanhã. Petrópolis: Vozes, 2014.

Rüsen, Jörn. “Formando a consciência histórica - para uma didática humanista da história." En Humanismo e didática da história (Jörn Rüsen), coordinado por Maria Auxiliadora Schmidt, Isabel Barca, Marcelo Fronza y Lucas Pydd Nechi, 19-42. Curitiba: W. A. Editores, 2015.

Schmidt, Maria Auxiliadora. "Cognição histórica situada: que aprendizagem é esta?" En Aprender História: perspectivas da Educação Histórica, coordinado por Maria Auxiliadora Schmidt y Isabel Barca, 21-50. Ijuí: Unijuí, 2009.

Shuter, Paul y John Child. Skills in History: Book 1: Changes. Londres: Heinemann Educational Books, 1990.

Sobanski, Adriane de Quadros, Edilson de Oliveira Chaves, João Luis da Silva Bertolini y Marcelo Fronza. Ensinar e aprender História: histórias em quadrinhos e cançôes. Curitiba: Editora Base, 2010.

Strauss, A. y J. Corbin. Basics of Qualitative Research. Grounded Theory, Procedures and Techniques. Newbury Park: Sage, 1991.

Walsh, W. H. Introdução à filosofia da História. Rio de Janeiro: Zahar, 1978. 